\title{
Severe Hypertriglyceridemia Causing Pancreatitis in a Child with New-onset Type-I Diabetes Mellitus Presenting with Diabetic Ketoacidosis
}

\author{
Pradeep Kumar Sharma, Maneesh Kumar, Dinesh Kumar Yadav' \\ Departments of Pediatric Critical Care and Pulmonology and ${ }^{1}$ Clinical Biochemistry, Sri Balaji Action Medical Institute, New Delhi, India
}

\section{Abstract}

The triad of pancreatitis, hypertriglyceridemia, and diabetic ketoacidosis and its treatment has not been extensively discussed in the pediatric literature. We report a 4-year-old child with severe hypertriglyceridemia, pancreatitis, and diabetic ketoacidosis. Hypertriglyceridemia and pancreatitis with diabetic ketoacidosis can be successfully managed with insulin and hydration therapy in children. Early recognition of this triad is important as insulin requirements, recovery duration, and prognosis can be altered.

Keywords: Diabetic ketoacidosis, pancreatitis, severe hypertriglyceridemia

\section{INTRODUCTION}

Around $25 \%$ of newly diagnosed diabetic children present with diabetic ketoacidosis at the onset. ${ }^{[1]}$ Severe hypertriglyceridemia (triglyceride $[\mathrm{TG}]>1000 \mathrm{mg} / \mathrm{dL}$ ) is another rare complication of ketoacidosis which increases the risk of acute pancreatitis. Pancreatitis attributable to hypertriglyceridemia was seen in $4 \%$ of diabetic ketoacidosis episodes in adults. ${ }^{[2]}$ However, the triad of acute pancreatitis caused by hypertriglyceridemia, along with diabetic ketoacidosis and its treatment, has not been extensively discussed in the pediatric literature. Only eight cases have been reported previously. We report the youngest child with the triad of severe hypertriglyceridemia, acute pancreatitis, and diabetic ketoacidosis.

\section{Case Report}

A 4-year-old female presented with vomiting, abdominal pain for 2 days, and progressive breathing difficulty and lethargy since last night. She had no fever, cough, or diarrhea. She also had polyuria, polydipsia, and $3 \mathrm{~kg}$ weight loss, despite good appetite during last 1 month. Past medical history was unremarkable and family history was unremarkable. On arrival, the child had Glasgow Coma Scale score of 11/15 (E3V3M5). She was severely dehydrated and had rapid breathing $(72 / \mathrm{min})$,

\begin{tabular}{|l|l|}
\hline \multicolumn{2}{|c|}{ Access this article online } \\
\hline Quick Response Code: & Website: \\
\hline & www.ijccm.org \\
\cline { 2 - 2 } & \\
\hline
\end{tabular}

pulse rate was $152 / \mathrm{min}$, and peripheral pulses were weak with cold peripheries. Capillary refill time was more than $5 \mathrm{~s}$. Her blood pressure was $76 / 40 \mathrm{mmHg}$ and temperature was $37.1^{\circ} \mathrm{C}$. Pupils were normal size, normally reacting, and meningeal signs were absent. Her abdomen was soft but tender. The rest of examination was normal. Her blood sugar was $404 \mathrm{mg} / \mathrm{dl}$. Blood gas revealed $\mathrm{pH} 6.85, \mathrm{HCO}_{3} 3 \mathrm{mmol} / \mathrm{l}$, and $\mathrm{pCO}_{2} 10 \mathrm{mmHg}$. Urine revealed glycosuria $4+$ and ketonuria (large). The child received normal saline bolus of $20 \mathrm{ml} / \mathrm{kg}$ and started on injection insulin and hydration therapy in the Pediatric Intensive Care Unit. Blood drawn for analysis was highly milky (lipemic) in appearance [Figure 1]. Laboratory values revealed hemoglobin $24.7 \mathrm{~g} \%$, total leukocyte counts $33.3 \times 10^{9} / \mathrm{L}$, neutrophils $57.6 \%$, lymphocytes $31.2 \%$, platelet count $288 / 10^{3} / \mathrm{mm}^{3}$, urea $18 \mathrm{mg} / \mathrm{dl}$, creatinine $0.6 \mathrm{mg} / \mathrm{dl}$, sodium $133 \mathrm{meq} / \mathrm{L}$, potassium $3.5 \mathrm{meq} / \mathrm{L}$, and initial glycated hemoglobin (HbAlc) 7.8\%. Serum TG was $13846 \mathrm{mg} / \mathrm{dl}$, total cholesterol $1267 \mathrm{mg} / \mathrm{dl}$, amylase $150 \mathrm{U} / \mathrm{L}$, and lipase $230 \mathrm{U} / \mathrm{L}$. Sensorium, general condition, and metabolic acidosis

Address for correspondence: Dr. Pradeep Kumar Sharma, Flat No 48, Pocket-7, Sector-21, Rohini, New Delhi - 110 086, India. E-mail: drsharma025@gmail.com

This is an open access article distributed under the terms of the Creative Commons Attribution-NonCommercial-ShareAlike 3.0 License, which allows others to remix, tweak, and build upon the work non-commercially, as long as the author is credited and the new creations are licensed under the identical terms.

For reprints contact: reprints@medknow.com

How to cite this article: Sharma PK, Kumar M, Yadav DK. Severe hypertriglyceridemia causing pancreatitis in a child with new-onset Type-I diabetes mellitus presenting with diabetic ketoacidosis. Indian J Crit Care Med 2017;21:176-8. 
gradually improved and diabetic ketoacidosis resolved over $36 \mathrm{~h}$. However, pain abdomen persisted. Ultrasound abdomen revealed bulky pancreas. The child was continued on injection insulin, intravenous fluids for further $48 \mathrm{~h}$. Pain abdomen improved and serum TG and cholesterol showed a decreasing trend [Table 1]. Repeat HbAlc at discharge was $14.2 \%$. Serum C-peptide was low $<0.3 \mathrm{ng} / \mathrm{ml}(0.81-3.85)$ and insulin antibodies were positive by enzyme immunoassay. The child was started on oral feeding and subcutaneous insulin. She was discharged 8 days after hospitalization. During follow-up, her lipid profile remained normal.

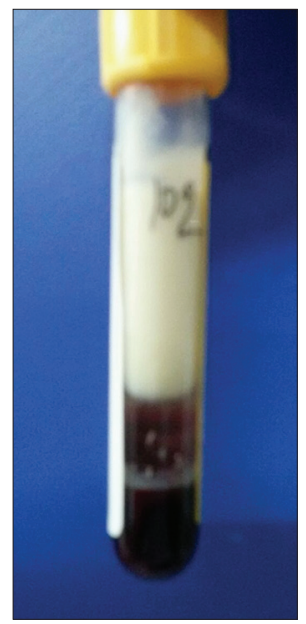

Figure 1: Lipemic appearance of the blood sample.

\begin{tabular}{|c|c|c|c|c|c|c|c|}
\hline \multirow[t]{2}{*}{ Laboratory test } & \multirow{2}{*}{$\begin{array}{l}\text { Reference } \\
\text { range }\end{array}$} & \multicolumn{6}{|c|}{ Days } \\
\hline & & 1 & 3 & 5 & 8 & 14 & 28 \\
\hline $\mathrm{TG}(\mathrm{mg} / \mathrm{dl})$ & $0-200$ & 13,846 & 5609 & 2215 & 675 & 490 & 90 \\
\hline Cholesterol (mg/dl) & $0-200$ & 1267 & 929 & 710 & 555 & 395 & 110 \\
\hline Amylase (U/L) & $25-125$ & 150 & 90 & 40 & 100 & 135 & 60 \\
\hline Lipase (U/L) & $13-60$ & 230 & 240 & 110 & 442 & 133 & 45 \\
\hline $\mathrm{pH}$ & $7.35-7.45$ & 6.85 & 7.36 & & & & \\
\hline $\mathrm{PCO}_{2}(\mathrm{mmHg})$ & $35-45$ & 10 & 28 & & & & \\
\hline $\mathrm{HCO}_{3}(\mathrm{mmol} / \mathrm{L})$ & $22-26$ & 3 & 15.8 & & & & \\
\hline $\mathrm{RBS}(\mathrm{mg} / \mathrm{dl})$ & $60-140$ & 404 & 222 & 102 & 242 & & \\
\hline
\end{tabular}

TG: Triglyceride; RBS: Random blood sugar

\section{Discussion}

This case highlights the challenges faced during management of severe diabetic ketoacidosis complicated by severe hypertriglyceridemia and resulting in acute pancreatitis. Our case presented with encephalopathy and possibility of cerebral edema, shock encephalopathy, or electrolyte disturbances was considered. Rapid improvement in Glasgow Coma Scale with volume resuscitation made strong possibility of shock encephalopathy as likely etiology. An important problem faced was an interpretation of laboratory measurements due to lipemic sample. Severe lipemia interferes with clinical laboratory testing through three mechanisms: (1) turbidity resulting in light scattering, (2) an increase in the nonaqueous phase of the sample, and (3) partitioning between the polar and nonpolar phases. Laboratory results were ambiguous in the case such as hemoglobin $24.7 \mathrm{mg} \%$ and $\mathrm{HbAlc}$ value of just $7.8 \%$. Serum electrolytes could be ascertained after $12 \mathrm{~h}$ which has an important bearing as serum corrected sodium needs to be monitored to prevent cerebral edema. Even after resolution of diabetic ketoacidosis, the child continued to have pain in the abdomen which necessitated further evaluation. This rare complication of acute pancreatitis was considered, and intravenous fluid and insulin were continued for prolonged duration.

Diabetic ketoacidosis is an absolute insulin deficiency state leading to increased fat mobilization by activating lipolysis in adipose tissue and releasing increased free fatty acids. This accelerates the formation of very low-density lipoprotein (VLDL) in the liver. Reduced activity of lipoprotein lipase in peripheral tissue decreases the removal of VLDL from the plasma, resulting in hypertriglyceridemia. Moderate hypertriglyceridemia is common during episodes of diabetic ketoacidosis. However, severe hypertriglyceridemia is rare, and clinicians should be aware that devastating consequences such as acute pancreatitis or lipidemia retinalis can occur. ${ }^{[3]}$ Review of available literature has shown 12 previous children with severe hyperlipidemia with diabetic ketoacidosis, and acute pancreatitis was present in only eight cases [Table 2]..$^{[3,4]}$ Our case is the youngest case to present with the triad of severe hyperlipidemia, acute pancreatitis, and diabetic ketoacidosis. The risk of mortality in severe diabetic ketoacidosis is

Table 2: Reported cases of pediatric DKA with hypertriglyceridemia and acute pancreatitis

\begin{tabular}{|c|c|c|c|c|}
\hline Patients & Age & Peak TG levels (mg/dl) & Management & Days to normalized of TG level \\
\hline Cywinski et al., $1965^{[5]}$ & 12.5 & $>1000$ & Hydration and insulin & 7 \\
\hline Slyper et al., $1994^{[6]}$ & 14 & 3119 & Hydration and insulin & NA \\
\hline Kadota-Shinozaki et al., $1997^{[7]}$ & 19 & 3386 & Hydration and insulin & 2 \\
\hline Hahn et al., 2010 $0^{[8]}$ & 20 & 15,000 & Hydration and insulin & 3 \\
\hline Lutfi et al., 2012 $2^{[4]}$ & 10 & 16,334 & Plasmapheresis & 2 \\
\hline Kota et al., 2012 $2^{[9]}$ & 12 & 1020 & Hydration and insulin & 3 \\
\hline Aboulhosn and Arnason, 2013 $3^{[10]}$ & 18 & 1724 & Hydration and insulin & 3 \\
\hline Wolfgram and Macdonald, $2013^{[11]}$ & 10 & 8300 & Hydration and insulin & 7 \\
\hline Our case & 4 & 13,846 & Hydration and insulin & 8 \\
\hline
\end{tabular}

TG: Triglyceride 
much higher in children below 5 years and association with hyperlipidemia, and acute pancreatitis can further increase this risk. Appropriate management includes intravenous fluid and insulin administration according to diabetic ketoacidosis guideline; however, some may require plasmapheresis, especially if having organ failure. ${ }^{[4]}$ A greater degree of clinical monitoring is required as laboratory results are usually delayed and unreliable.

\section{ConcLusion}

Severe hypertriglyceridemia and acute pancreatitis can be seen with diabetic ketoacidosis in children below 5 years. Early recognition of this triad has important implications in the management of the patient as insulin requirements, recovery duration, and prognosis can be altered.

\section{Financial support and sponsorship}

Nil.

\section{Conflicts of interest}

There are no conflicts of interest.

\section{References}

1. Rewers A, Klingensmith G, Davis C, Petitti DB, Pihoker C, Rodriguez B, et al. Presence of diabetic ketoacidosis at diagnosis of diabetes mellitus in youth: The Search for Diabetes in Youth Study.
Pediatrics 2008;121:e1258-66.

2. Nair S, Yadav D, Pitchumoni CS. Association of diabetic ketoacidosis and acute pancreatitis: Observations in 100 consecutive episodes of DKA. Am J Gastroenterol 2000;95:2795-800.

3. Saengkaew T, Sahakitrungruang T, Wacharasindhu S, Supornsilchai V. DKA with severe hypertriglyceridemia and cerebral edema in an adolescent boy: A case study and review of the literature. Case Rep Endocrinol 2016;2016:7515721.

4. Lutfi R, Huang J, Wong HR. Plasmapheresis to treat hypertriglyceridemia in a child with diabetic ketoacidosis and pancreatitis. Pediatrics 2012;129:e195-8.

5. Cywinski JS, Walker FA, White H, Traisman HS. Juvenile diabetes mellitus associated with acute pancreatitis. Acta Paediatr Scand 1965;54:597-602.

6. Slyper AH, Wyatt DT, Brown CW. Clinical and/or biochemical pancreatitis in diabetic ketoacidosis. J Pediatr Endocrinol 1994;7:261-4.

7. Kadota-Shinozaki A, Nakamura T, Hidaka H, Kojima H, Yasuda H, Kashiwagi A, et al. Diabetic lipemia with maturity-onset diabetes of the young. Intern Med 1997;36:571-4.

8. Hahn SJ, Park JH, Lee JH, Lee JK, Kim KA. Severe hypertriglyceridemia in diabetic ketoacidosis accompanied by acute pancreatitis: Case report. J Korean Med Sci 2010;25:1375-8.

9. Kota SK, Jammula S, Kota SK, Meher LK, Modi KD. Acute pancreatitis in association with diabetic ketoacidosis in a newly diagnosed type 1 diabetes mellitus patient; case based review. Int J Clin Cases Investig 2012;4:54-60.

10. Aboulhosn K, Arnason T. Acute pancreatitis and severe hypertriglyceridaemia masking unsuspected underlying diabetic ketoacidosis. BMJ Case Rep 2013;2013. pii: Bcr2013200431.

11. Wolfgram PM, Macdonald MJ. Severe hypertriglyceridemia causing acute pancreatitis in a child with new onset type I diabetes mellitus presenting in ketoacidosis. J Pediatr Intensive Care 2013;2:77-80. 